\title{
Real-time monitoring of copper ions-induced cytotoxicity by EIS cell chips
}

\author{
Elisabetta Primiceria ${ }^{a}, *$ Maria Serena Chiriacò ${ }^{a}$, Eliana D’Amone ${ }^{a}$, Emanuela Urso ${ }^{\mathrm{b}}$, \\ Rodica Elena Ionescu ${ }^{a}$, Antonia Rizzello $^{\mathrm{b}}$, Michele Maffia ${ }^{\mathrm{b}}$, Roberto Cingolani ${ }^{\mathrm{a}, 1}$, \\ Ross Rinaldi ${ }^{\mathrm{a}}$, Giuseppe Maruccio ${ }^{\mathrm{a}, * *}$ \\ a Scuola Superiore ISUFI, University of Salento, CNR-Institute of Nanoscience, Via per Arnesano, 73100 Lecce, Italy \\ ${ }^{\mathrm{b}}$ Laboratory of General Physiology, Department of Biological and Environmental Science and Technology, University of Salento, S.P. 6, Lecce - Monteroni, 73100 Lecce, Italy
}

\section{A R T I C L E I N F O}

\section{Article history:}

Received 8 February 2010

Received in revised form 2 April 2010

Accepted 21 April 2010

Available online 29 April 2010

\section{Keywords:}

Cell chip

Cell-based assay

Cytotoxicity

Impedance-based sensors

AFM on cells

\begin{abstract}
A B S T R A C T
An important goal of biomedical research is the development of tools for high-throughput evaluation of drug effects and cytotoxicity tests. Here we demonstrate EIS cell chips able to monitor cell growth, morphology, adhesion and their changes as a consequence of treatment with drugs or toxic compounds. As a case study, we investigate the uptake of copper ions and its effect on two cell lines: B104 and HeLa cells. For further understanding, we also carried out in parallel with EIS studies, a complete characterization of cell morphology and changes induced by copper ions through complementary methodologies (including state-of-the-art AFM, viability test and Western blot). Our results reveal a strong correlation between EIS data and both MTT test and AFM characterization so our chip can be used as powerful tools in all biology lab in combination with other standard methods giving additional information that can be useful in a complete and deep investigation of a biological process. This chip can be used even alone replacing in vitro drug tests based on conventional biochemical methods, being very cheap and reusable and allowing to perform cytotoxicity tests without using any expensive reagent or equipment.
\end{abstract}

(C) 2010 Elsevier B.V. All rights reserved.

\section{Introduction}

Viability assays and cytotoxicity tests are important to evaluate possible side effects of potentially new drugs. However, widely used biochemical methods, such as MTT, neutral red uptake assays and adenosine-5'-triphosphate (ATP) measurements, are laborious and time consuming requiring complex steps with multiple reagents. In addition, these techniques are invasive and destructive against target cells, making impossible to monitor a dynamic process. Therefore, the development of new tools for real-time and high-throughput screening is important for biomedical research (Smith, 2007). On-chip cell-based assays are emerging as a valid alternative with the potential to replace in vivo tests on animals during the evaluation of side effects of new drug candidates. In this respect, electrochemical impedance spectroscopy (EIS) represents a suitable transduction technique (Katz and Willner, 2003) enabling a non-invasive, real-time study of cell behaviour as proposed firstly by Giaever and Keese (Giaever and Keese, 1991, 1993; Keese and Giaever, 1994). Indeed, cell attachment and spreading induce

\footnotetext{
* Corresponding author. Tel.: +39 0832 298368; fax: +39 0832295708.

** Corresponding author. Tel.: +39 0832 298218/5713; fax: +39 0832295708.

E-mail addresses: elisabetta.primiceri@unisalento.it (E. Primiceri), giuseppe.maruccio@unisalento.it (G. Maruccio).

1 Present address: Italian Institute of Technology, Genova-Morego, Italy.
}

detectable changes in the impedance, which is correlated to cell viability, adhesion and cytoskeleton organization. As a consequence, EIS has been already used to study several cellular processes such as cell micromotion, cell attachment and spreading, cell concentration and growth or apoptosis (Giaever and Keese, 1991, 1993; Keese and Giaever, 1994; Xiao et al., 2002; Xiao and Luong, 2003; Arndt et al., 2004; Yeon and Park, 2005; Cheng et al., 2007). Recently, EIS has been also successfully used for cytotoxicity tests on different cell lines, such as human hepatocellular carcinoma cells (Yeon and Park, 2005; Minseok et al., 2008), fibroblastic cells (Xiao et al., 2002; Xiao and Luong, 2003; Ceriotti et al., 2007a,b), cells from kidney of male monkey or human colon adenocarcinoma (Ehret et al., 1997).

Here, we fabricated EIS cell chips able to monitor cell adhesion and morphological changes and, for the first time, we used them in combination with off-chip methodologies (AFM, viability test and Western blot) to demonstrate the biological meaning of the data obtained by EIS. This approach allowed us to perform a complete characterization of the changes induced by copper ions on two cell lines (B104 and HeLa cells). Our results revealed a strong correlation between EIS data and both MTT test and AFM characterization providing further insight on the effects of copper which is an essential trace metal in human nervous system and has a key role in its development. In fact, several diseases, as amyotrophic lateral sclerosis, Menkes and Wilson diseases, are due to disorders of copper metabolism and when its homeostasis is perturbed this metal reveals a strong toxicity (Ceriotti et al., 2007b). Because of 

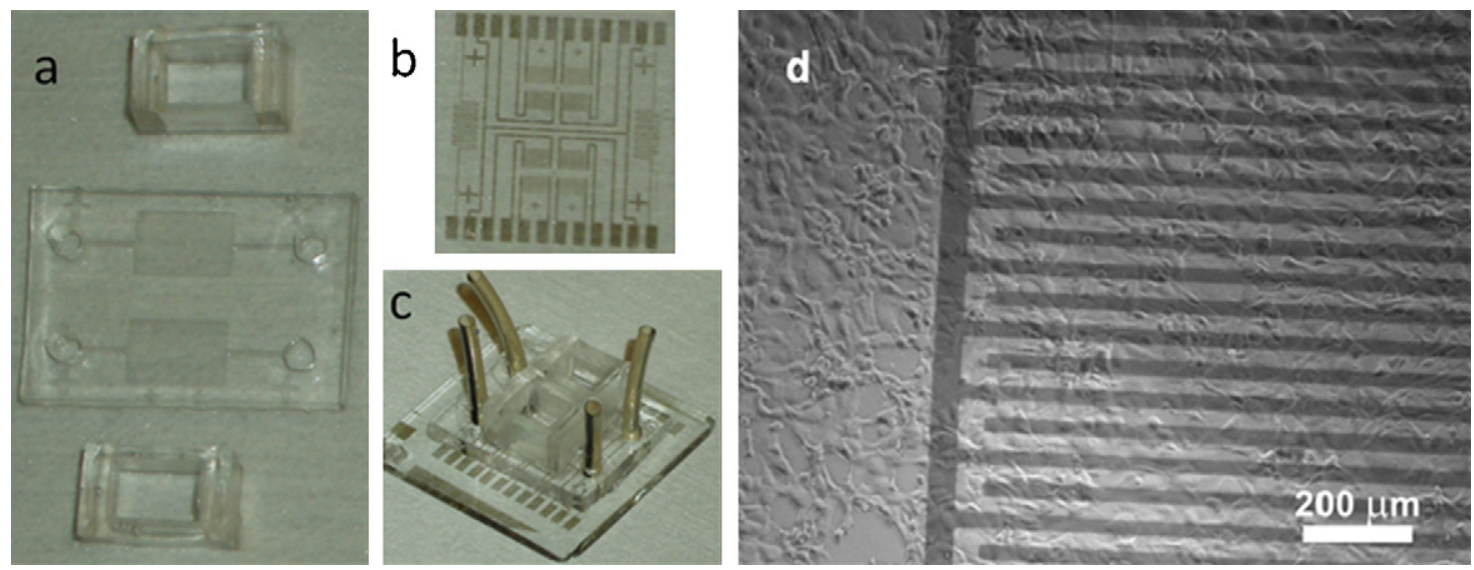

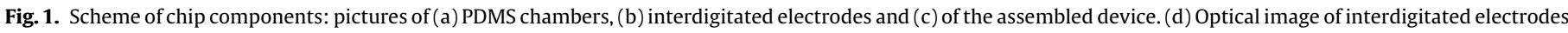
and cells on the top: cells are optically accessible through an inverted microscope during the measurements.

its redox properties, if in excess, copper can catalyze the formation of radical species such as ROS (Reactive Oxygen Species), able to destroy several cell structures (Valko et al., 2005; Hultberg et al., 1995). Moreover, recent studies also established the role of this metal in the pathogenesis of Alzheimer's disease and in other diseases associated with prion formation (Waggoner et al., 1999). ${ }^{2}$ This approach proves the compatibility and complementarity of EIS technique with the standard technique used in all biological laboratories and demonstrates that the chip can be easily introduced as rapid and new technique in biological investigation giving new and dynamic data.

\section{Materials and methods}

\subsection{Microfabrication of the cell chip}

Our chips consist of a cell culture chamber made of PDMS (Polydimethylsiloxane) incorporating ITO (Indium Tin Oxide) or $\mathrm{Cr} / \mathrm{Au}$ interdigitated electrodes on glass substrates (with a line-space period of $40 \mu \mathrm{m}$ and covering a $2 \mathrm{~mm} \times 2.5 \mathrm{~mm}$ area). PDMS cell culture chambers were realized by replica molding from a hard master, while the electrodes were fabricated by optical lithography (using a Karl Suss MJB3 mask aligner and AZ5214B resist). In the case of ITO electrodes, glass substrates with a superficial ITO layer (Visionteck) were used and the electrode pattern was obtained by chemical etching. Gold electrodes were fabricated by thermal evaporation of $\mathrm{Cr} / \mathrm{Au}$ ( $3 \mathrm{~nm} / 10 \mathrm{~nm}$ ) on glass substrates (Visionteck) and subsequent lift-off. All materials are biocompatible and the final device (Fig. 1) is transparent (or semitransparent) in order to be mounted on an inverted microscope for real-time monitoring of cells during measurements. Each chip includes control and treatment chambers to facilitate an accurate comparison. Moreover, drugs and compounds to be evaluated can be provided in small amounts and a quick and controllable way by means of microfluidic modules including channels and valves (Minseok et al., 2008).

\footnotetext{
2 The main proteins associated with Alzheimer's and prion diseases (APP, Amyloid Precursor Protein and $\mathrm{PrP}^{\mathrm{C}}$, Cellular Prion Protein) have binding sites for copper and they probably play a role in copper metabolism (Waggoner et al., 1999; Inestrosa et al., 2005). In particular, $\operatorname{Pr}^{C}$ binds copper ions through its peptide repeats (octarepeat region), a highly conserved region in the $\mathrm{N}$-terminal end. The octarepeat region is highly selective for $\mathrm{Cu}^{2+}$ and the binding of the metal is $\mathrm{pH}$ dependent. In addition, the octarepeat region of $\operatorname{PrP}^{C}$ can also reduce copper in vitro from $\mathrm{Cu}^{2+}$ to $\mathrm{Cu}^{1+}$, facilitating its incorporation into the cells (Waggoner et al., 1999; Inestrosa et al., 2005).
}

\subsection{Cell culture and treatments}

B104 neuroblastoma cells derived from rat Central Nervous System, represent an appropriate cell model to investigate the link between copper toxicity and $\operatorname{PrP}^{\mathrm{C}}$ (Cellular Prion Protein) role (Monnet et al., 2003). In fact, other mouse neuronal cell lines express low levels of endogenous prion protein or its highly glycosylated forms. In contrast, rat B104 neuroblastoma cells abundantly express the $\mathrm{N}$-glycosylated isoform of cellular prion protein. As term of comparison, the HeLa human cervix carcinoma cell line was also investigated.

Cells were cultured under standard conditions at $37^{\circ} \mathrm{C}$ and $5 \% \mathrm{CO}_{2}$ in Dulbecco's Modified Eagle Medium (DMEM) (Sigma-Aldrich) supplemented with 10\% fetal bovine serum (FBS, Sigma-Aldrich), $1 \mathrm{mM}$ sodium pyruvate and antibiotics. The chips were then washed in ethanol and cells were seeded in each sensor chamber at a concentration of $10^{5}$ cells $/ \mathrm{ml}$. Then cells were allowed to grow for at least $24 \mathrm{~h}$. Both cell lines were stimulated with $\mathrm{CuCl}_{2}$ solutions in DMEM or L-15 media at different concentrations (25, $50,100,250$ and $500 \mu \mathrm{M})$ and for different duration time $(2,4,6$, and $24 \mathrm{~h}$ ) depending on the experiments.

\subsection{Cytotoxicity test (MTT test)}

MTT (3-[4,5-dimethylthiazol-2-yl]-2,5-diphenyltetrazolium bromide) is a water soluble tetrazolium salt that is converted to an insoluble purple formazan by active mitochondrial dehydrogenases of living cells. Dead cells do not induce this conversion. Thus, the amount of insoluble purple compound, which can be quantified spectrophotometrically, is proportional to the number of living cells. This reaction has been largely employed to measure cell proliferation or cytotoxicity.

In our experiments we dissolved MTT(Sigma-Aldrich), $5 \mathrm{mg} / \mathrm{ml}$, in DMEM. This MTT solution was then added in each culture well and incubated for $3 \mathrm{~h}$. Then to dissolve cells and solubilize the converted compound, a solution of $\mathrm{HCl}$ in isopropanol was added and the adsorbance was measured at $570 \mathrm{~nm}$. Each experiment has been repeated three times and the mean value for each condition has been reported in the graph (Fig. 2).

\subsection{EIS measurements on cell chip}

An impedance analyzer Autolab PGSTAT30 (EcoChemie) equipped with a FRA2 module was used for measurements. Impedance data were recorded in the frequency range between 1 


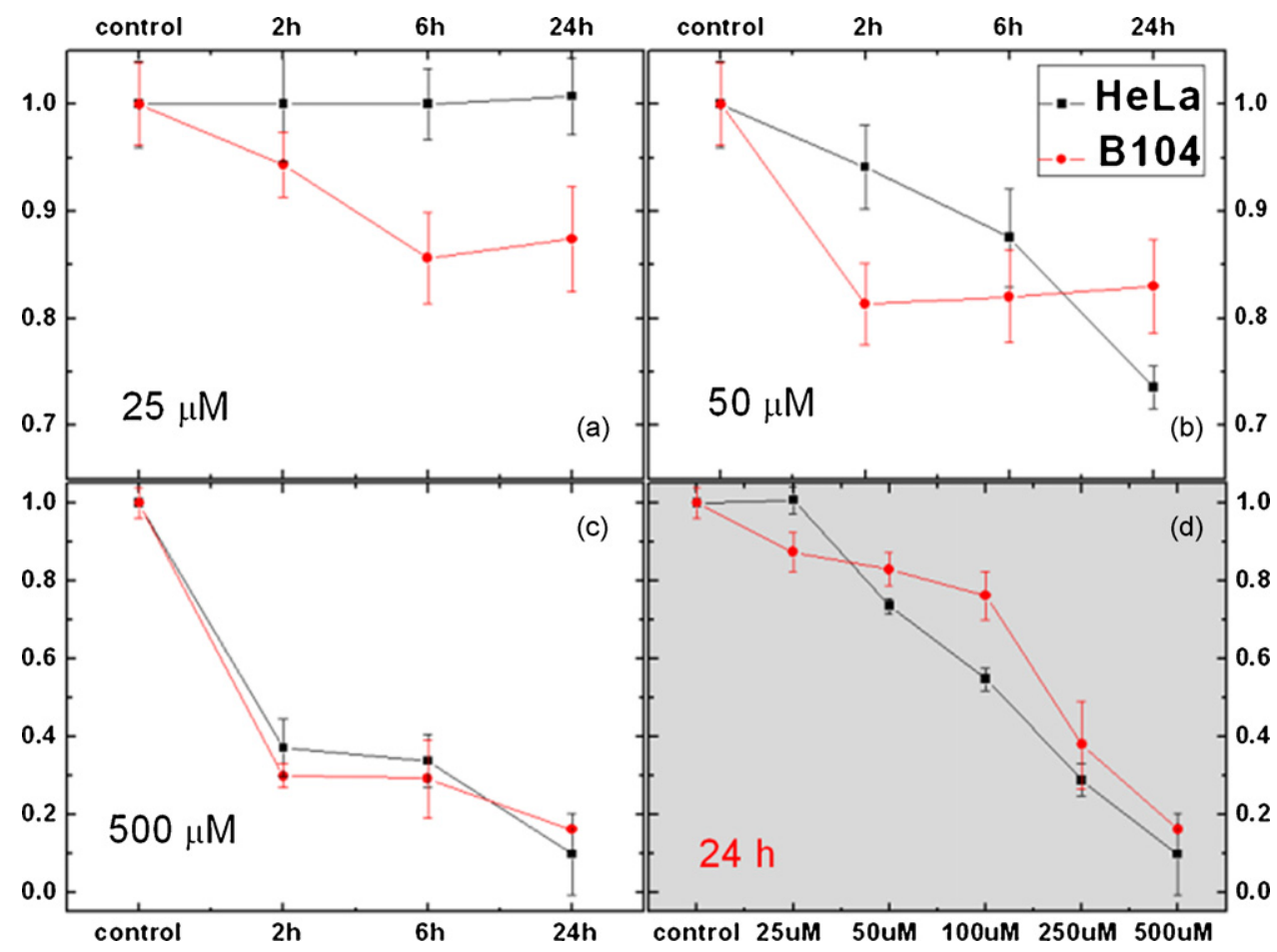

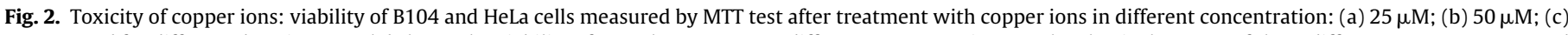

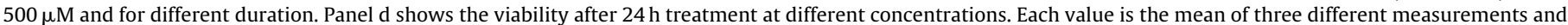
the error bars show the standard deviation on the measurements.

and $10^{6} \mathrm{~Hz}$ using sinusoidal ac voltage with a $15 \mathrm{mV}$ RMS amplitude. No dc bias potential was applied $\left(V_{\mathrm{DC}}=0 \mathrm{~V}\right)$.

All the experiments were performed in L-15 medium (Leibovitz) from Sigma-Aldrich, a conventional cell culture medium formulated for use in carbon dioxide free systems to maintain them outside the incubator during the measurement. A redox couple $\mathrm{K}_{3}\left[\mathrm{Fe}(\mathrm{CN})_{6}\right] / \mathrm{K}_{4}\left[\mathrm{Fe}(\mathrm{CN})_{6}\right](1: 1)$ (Sigma-Aldrich) was added to the medium to a final concentration of $10 \mathrm{mM}$. This concentration allows to increase the conductivity of the solution and the sensitivity of the system but it is low enough to avoid any possible toxic effect on the cells (as demonstrated by MTT tests, data not shown).

\subsection{Atomic force microscopy (AFM)}

AFM imaging has been performed using a Bioscope 2 system (Veeco Instruments Inc.) mounted on an inverted optical microscope (Zeiss Observer Z1, Carl Zeiss). Fixed and dried cells were imaged in contact mode in air. For contact mode imaging, in order to avoid cell damage we used V-shaped silicon nitride cantilevers with very low force constants, ranging from 0.01 to $0.05 \mathrm{~N} / \mathrm{m}$ (Microlever, MLCT-AUNM, Veeco).

\subsection{Western blot analysis}

Whole cell extracts were prepared in ice-cold modified RIPA buffer (50 mM Tris-HCl, pH 7.4, 1\% NP-40, 0.25\% Na-deoxycholate, $150 \mathrm{mM} \mathrm{NaCl}, 1 \mathrm{mM}$ EDTA, $1 \mathrm{mM} \mathrm{Na} \mathrm{VO}_{4}, 1 \mathrm{mM} \mathrm{NaF}$ ) containing a protease inhibitor mixture (Sigma-Aldrich). Samples were centrifuged at $14,000 \times g$ for 15 min and supernatants collected. Deglycosylation of extracts was performed by incubation with $\mathrm{N}$ glycosidase $\mathrm{F}$ (Sigma-Aldrich) for $3 \mathrm{~h}$ at $37^{\circ} \mathrm{C} .30 \mu \mathrm{g}$ proteins were loaded and run onto $10 \%$ SDS polyacrylamide gels. Separated protein bands were transferred onto a nitrocellulose filter and aspecific sites were blocked with PBS-0.1\% Tween containing 5\% non-fat milk. The membrane was incubated with monoclonal primary antibody against $\operatorname{PrP}^{\mathrm{C}}$ (Sigma-Aldrich) overnight at $4{ }^{\circ} \mathrm{C}$ and then with peroxidase-labeled secondary antibody (Santa Cruz Biotechnology, Inc.) at $37^{\circ} \mathrm{C}$ for $1 \mathrm{~h}$. After washes in PBS-0.1\% Tween, band detection was performed by a horseradish peroxidase-based chemiluminescent detection system (ECL, Amersham).

Blot images were scanned and densitometric analysis performed by Image software. Results were normalized against $\beta$-actin and expressed as means \pm standard error (S.E.) from six experiments. Statistical significance in difference between band intensities was determined by Student's $t$-test $\left({ }^{*} p<0.05\right)$.

\section{Results and discussion}

In the present study we demonstrate the ability of EIS cell chips to monitor changes in cell morphology and study the effect of copper ions on two different cell lines (B104 and HeLa). Moreover, thanks to the combination of different techniques and the correlation of their results, we achieved a deeper understanding of the phenomenon.

Firstly, we tested the effect of copper ions on B104 and HeLa cell viability. The behaviour of the two cell lines is quite different, as shown in the four panels in Fig. 2. B104 cells were found to be very sensitive to copper salt and MTT tests revealed a toxic effect of this compound even at low concentration ( $25 \mu \mathrm{M}$; Fig. 2a). Specifically, B104 cell viability starts to decrease already after $2 \mathrm{~h}$ treatment, whereas HeLa viability remains unchanged with respect to control condition at all times (Fig. 2a). At intermediate copper concentrations $(50 \mu \mathrm{M})$ HeLa cells start to die, whereas for B104 cells the loss of viability drops to about $80 \%$ already after $2 \mathrm{~h}$ treatment and it keeps constant for longer exposures (Fig. 2b). At the higher copper concentration $(250-500 \mu \mathrm{M})$ the viability of both cell lines is strongly reduced and they exhibit the same behaviour (Fig. 2c).

A toxic compound, such as copper salt, typically causes cell death by inducing molecular pathways. Cytoskeletal proteins are the mediators or effectors in different signaling pathways and are responsible for cell structure and shape. So a toxic effect normally induces a morphological change before cell death. For this reason, 

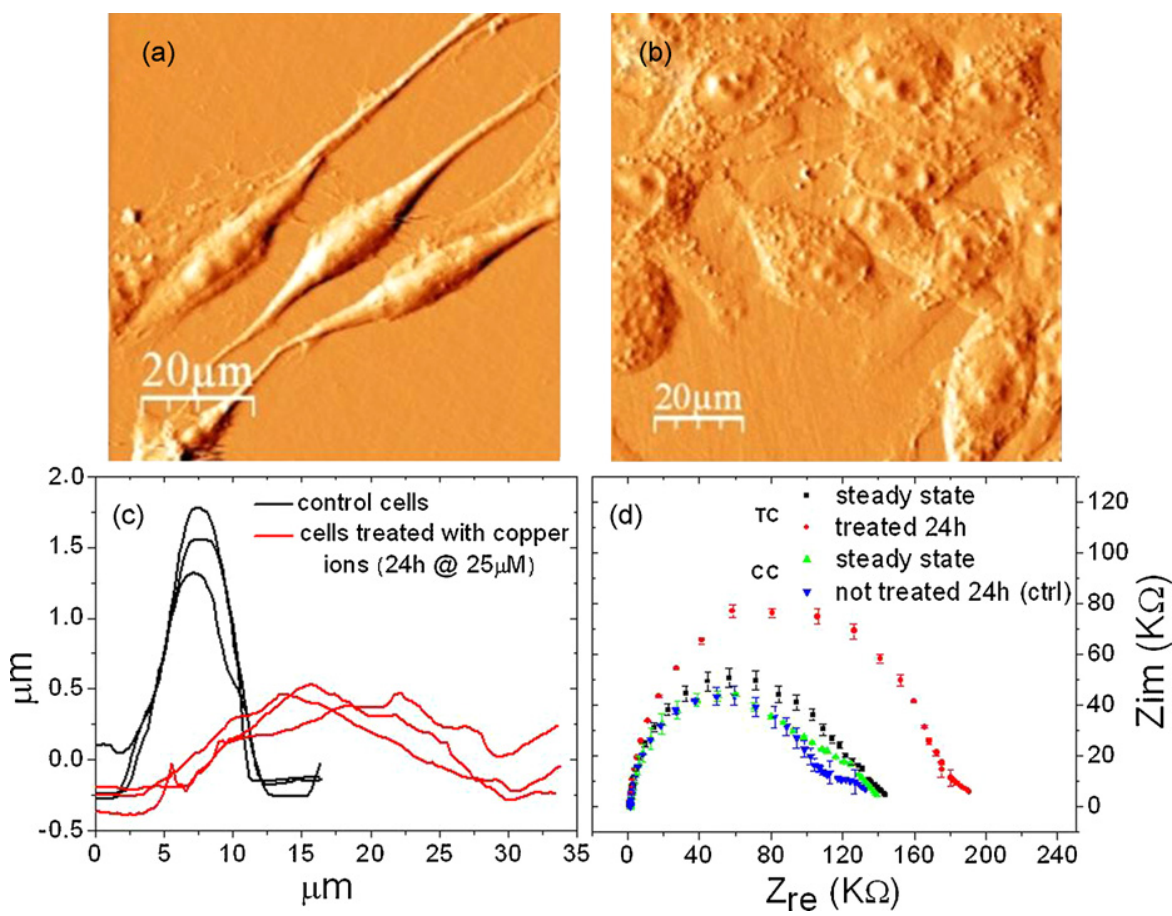

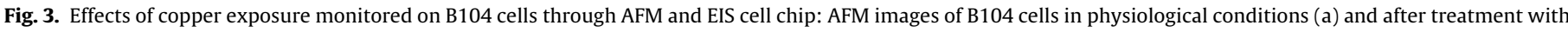

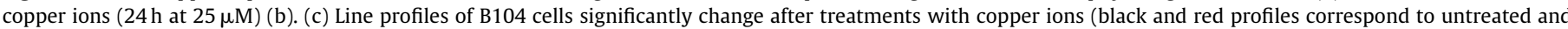

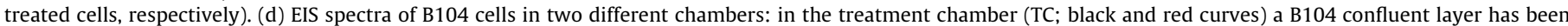

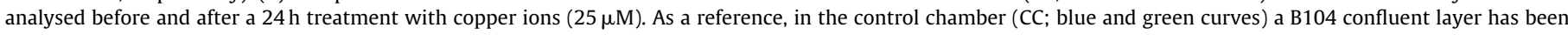

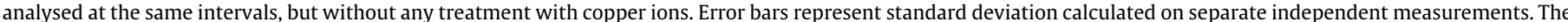

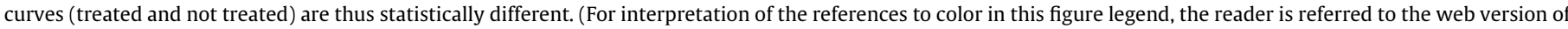
the article.)

to test the effect of treatments on cell morphology, AFM studies were carried out using a Bioscope 2 system (Leporatti et al., 2009) (Veeco Instruments Inc., Santa Barbara, CA, USA).

In Fig. 3a, a typical AFM image of B104 cells in physiological conditions is shown. Before treatment, the surface of the cells is smooth and the cell height is around $2 \mu \mathrm{m}$ (see the cross-section profiles reported in Fig. 3c). After short treatments ( $2 \mathrm{~h}$ with $25 \mu \mathrm{M}$ copper concentration) no significant changes in morphology are detectable (data not shown). A $24 \mathrm{~h}$ treatment led to significant changes in the shape of the cells (Fig. 3b), which started to spread onto the surface becoming larger and thinner than the control ones (the height decreased to about $0.5 \mu \mathrm{m}$, as shown in Fig. 3c).

After these complementary (off-chip) investigations, we tested the effect of copper ions using our EIS chips. For this purpose, B104 cells were seeded and cultured directly in the devices. As a rule, cells were kept in culture more than $24 \mathrm{~h}$ to reach the steady state. A small ac voltage (RMS amplitude $15 \mathrm{mV}$ ) was used to measure the complex impedance as a function of frequency (the dc voltage was kept to $0 \mathrm{~V}$ ). In Fig. 3d, we report typical results from a control chamber with untreated cells and a second chamber containing cells to be exposed to a $\mathrm{CuCl}_{2}$ solution. Before treatment, an electron transfer resistance of about $140 \mathrm{k} \Omega$ is detectable in both cases. This value remains substantially unchanged in the reference chambers after $48 \mathrm{~h}$ in culture without the toxicant to evaluate ageing effects. Just a small decrease in the impedance (about $10 \mathrm{k} \Omega$ ) can be observed and it can be attributed to the detachment of some dead cells after medium change (before each measurement we change DMEM with L-15 medium). On the contrary, exposure to copper ions leads to significant increases in the resistance of the treated chambers, as shown in Fig. 3d, where the red curve corresponds to a $24 \mathrm{~h}$ treatment with a $25 \mu \mathrm{M}$ copper solution. Here the resistance increases from $\approx 140$ to $\approx 190 \mathrm{k} \Omega$ as the cells spread on the electrodes, altering the effective area available for current flow (for the redox reaction to take place). This is in agreement with the morphological changes observed by AFM (where cells become larger and thinner than the control) and with the viability data, indicating that such chip can be employed for a rapid screening on different cell lines. To demonstrate the ability of our chip to monitor in realtime a biological process we report impedance spectra at different intervals time (Fig. 4). In the inset in Fig. 4 the increase in $R_{\mathrm{et}}$ as a function of time is also shown. Before comparing these results with MTT, a short discussion is necessary. In the MTT assay, mitochondrial dehydrogenase converts the yellowish MTT to an insoluble

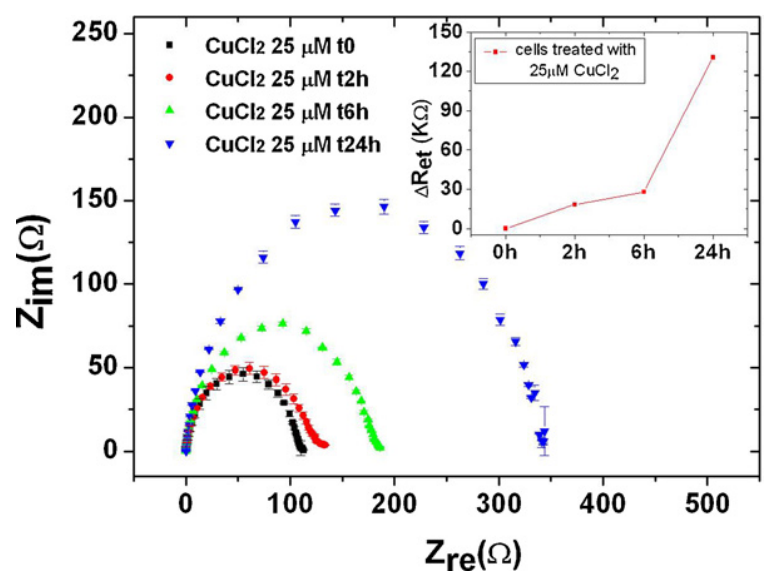

Fig. 4. Real-time monitoring the effect of copper ions on B104 cells through EIS cell chip: EIS spectra of B104 cells before (black) and after $2 \mathrm{~h}$ (red), $6 \mathrm{~h}$ (green) and $24 \mathrm{~h}$ (blue) treatment with copper ions $(25 \mu \mathrm{M})$. As longer is the treatment as bigger is the $R_{\mathrm{et}}$ caused by the spreading of cells. Inset: increase of $R_{\mathrm{et}}$ as function of time. $\Delta R_{\mathrm{et}}$ has been calculated as $\Delta R_{\mathrm{et}}=R_{\mathrm{et}}\left(t_{x}\right)-R_{\mathrm{et}}\left(t_{0}\right)$. (For interpretation of the references to color in this figure legend, the reader is referred to the web version of the article.) 

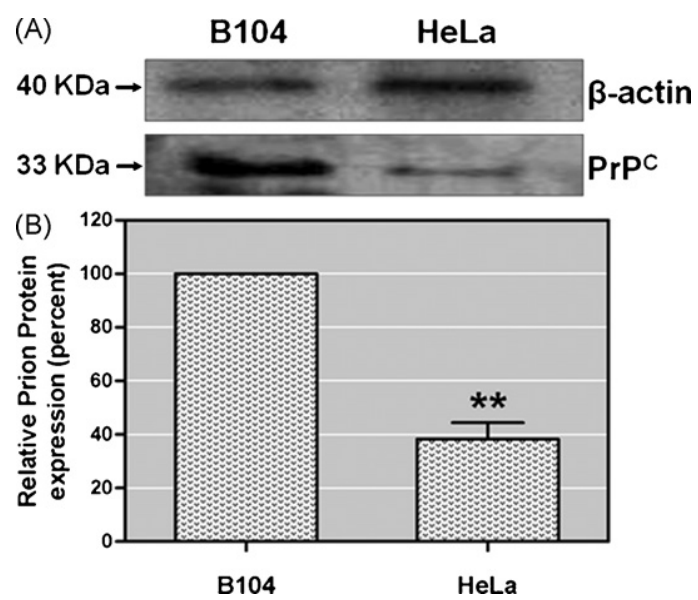

Fig. 5. Prion protein expression: Western blot analysis in B104 and HeLa cell lines. Panel A: whole lysates ( $30 \mu \mathrm{g}$ protein) were separated by SDS-PAGE and probed with monoclonal anti-prion protein antibody. Blot is representative of six experiments. Panel B: prion protein band intensities were quantified by ImageJ software and normalized to $\beta$-actin levels $\left({ }^{* *} p<0.01\right)$.

purple compound. Only living cells with active mitochondria are able to perform this conversion so the MTT assay measures cell viability based only on mitochondrial activity. For this reason in the case of MTT only metabolic and energetic alterations are probed, while through our chip we monitor changes in cytoskeleton organization (as actin fibers formation) that reflect stress and suffering conditions, which continue to increase also after the MTT signal stabilizes.

To further test our biochips and as a term of comparison to gain further insight, we performed the AFM and on-chip investigations on HeLa cell line, showing a different expression level of $\operatorname{Prp}^{C}$ with respect to B104 cells. This has been demonstrated by the immunoblotting analysis shown in Fig. 5: the expression of $\operatorname{Prp}^{C}$ is $2.6 \pm 0.4$-fold higher in B104 than in HeLa cells. This finding could at least partly account for the more pronounced sensitivity to copper exhibited by B104 cells. In fact, a role for prion protein in mediating copper uptake has been demonstrated in this cell model (Urso et al., 2009). It follows that copper ions enter in the B104 cells more easily than in the HeLa cell model and, when exceeding the cytosolic buffer capacity, they give rise to more consistent oxidative phenomena with consequent cell damage. To further support the involvement of prion protein in cell copper transport, $\mathrm{PrPC}_{-}$ deficient cells have been shown to exhibit a reduced copper content (Brown et al., 1997). In addition, altered brain copper levels have been found in $\mathrm{Prp}^{-/-}$and $\mathrm{PrP}^{\mathrm{C}}$-overexpressing mice (Brown, 2003).

In Fig. 2d we can observe that B104 loss of cell viability after $24 \mathrm{~h}$ treatment with $25 \mu \mathrm{M}$ copper is higher with respect to HeLa cells. In response to higher copper concentrations (except for the extreme values), the decrease in B104 cell viability is less accentuated than observed for HeLa cells. In the light of the high level of $\mathrm{PrP}^{\mathrm{C}}$ expression by $\mathrm{B} 104$ cells, this could be explained by hypothesizing that copper toxicity can be partly counterbalanced by the $\mathrm{PrP}^{\mathrm{C}}$-dependent activation of anti-oxidant mechanisms (Milhavet et al., 2000; Rachidi et al., 2003). Accordingly, the impairment of brain anti-oxidant enzyme activities (i.e. Cu/Zn Superoxide dismutase) has been detected in PrPC-deficient cells (Brown et al., 1997) and mice (Klamt et al., 2001; Dal Pizzol et al., 2000; Pereira et al., 2001).

AFM investigations were carried out on HeLa cultures treated with $500 \mu \mathrm{M} \mathrm{CuCl}_{2}$ for $2-24 \mathrm{~h}$ (Fig. 6). In physiological conditions, the surface of the cells is quite smooth and their height is around $2 \mu \mathrm{m}$ (Fig. 6a). After $2 \mathrm{~h}$ treatment with $500 \mu \mathrm{M}$ copper ions, cells appear to spread onto the surface becoming thinner than the control ones (about $1 \mu \mathrm{m}$ ), as observed also for B104 cell line (Fig. 6b). However, longer treatments lead to cell detachment (as suggested by the round shape some of them assumes, see Fig. 6d). After $24 \mathrm{~h}$ the cell morphology is the same as after $2 \mathrm{~h}$ copper exposure. In addition, most of cells are detached from the surface (see optical images in the insets of Fig. 6e acquired before and after treatment). For this reason we decided to show the results at this concentration to show the ability of our device to detect both morphological changes and detachment phenomena.

So, the same cytotoxic effects were also monitored using the biochips. Specifically we measured impedance spectra after 2 and $24 \mathrm{~h}$ treatments. The measured electron transfer resistance in the case of a $2 \mathrm{~h}$ treatment (red curve in Fig. 6e) was found to be slightly larger than the control one because of a slight spreading of the cells on the electrodes (see the corresponding AFM image in Fig. 6b). Then, after $24 \mathrm{~h}$ treatment, the induced cell detachment resulted in a significant decrease of the impedance (green curve) since a large area of the electrodes became free and available for current flow.
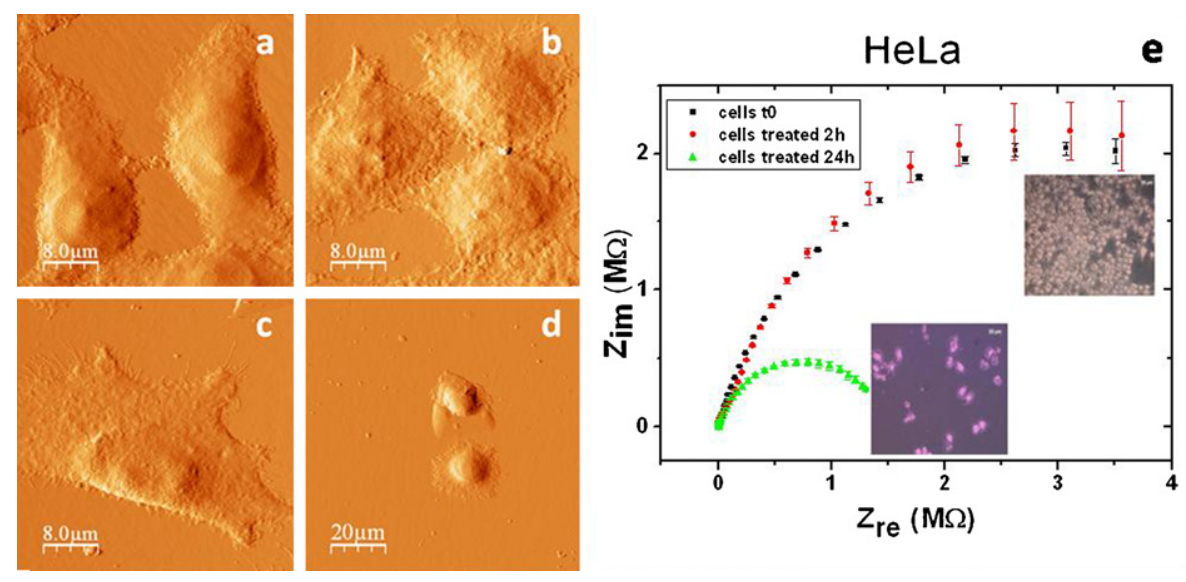

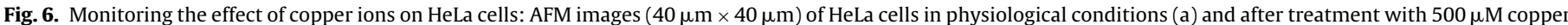

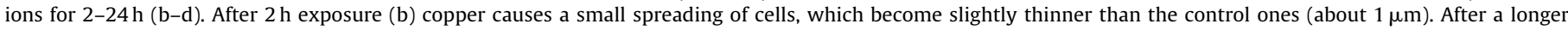

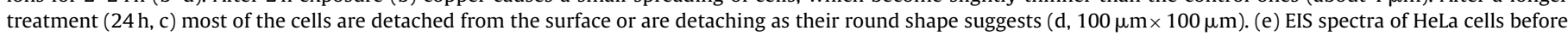

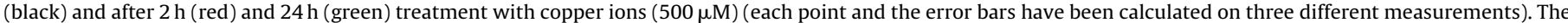

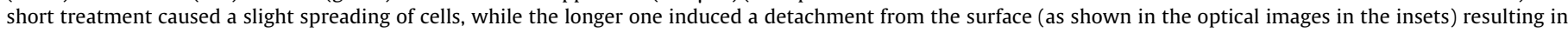

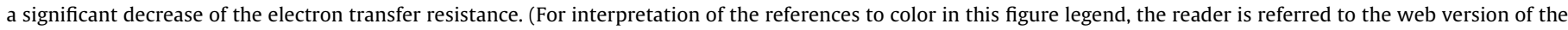
article.) 


\section{Conclusion}

In conclusion in this work, we report the successful application of EIS-based devices to monitor the toxicity of copper ions on cultured cells. Impedance measurements on cellular systems have been shown to be effective tools for monitoring in real-time cellular behavior and performing cytotoxicity assays, due to the strong correlation between EIS spectra, MTT and AFM data. All the data obtained through these techniques contribute to gain a better comprehension of the toxic effect of copper salt. Moreover, the comparison between EIS and the other techniques prove the feasibility of on-chip assays which provide additional information compared to traditional biochemical tests because they allow to probe morphological and structural alterations that correspond to early events in toxicological process. As a consequence, beyond to become fundamental tools for drug discovery, on-chip assays can be expected to have applications in numerous studies taking also into account that by means of the same cell chips, adherent cells can be monitored during cultivation and dynamic processes can be non-invasively studied. In particular thanks to multiplexing and integration in more complex fluidic networks, these sensors can be particularly useful in the field of drug discovery in order to test with high-throughput a large library of drugs or to test the effect of the same drug on different cell lines.

\section{Acknowledgments}

This work was supported by Italian Institute of Technology (IIT) and by MIUR FIRB Project No. BNE03FMCJ_003.

\section{References}

Arndt, S., Seebach, J., Psathaki, K., Galla, H.J., Wegener, J., 2004. Biosens. Bioelectron. $19,583-594$.
Brown, D.R., Qin, K., Herms, J.W., Madlung, A., Manson, J., Strome, R., Fraser, P.E., 1997. Nature 390, 684-687.

Brown, D.R., 2003. J. Neurochem. 87, 377-385.

Ceriotti, L., Ponti, J., Colpo, P., Sabbioni, E., Rossi, F., 2007a. Biosens. Bioelectron. 22, 3057-3063.

Ceriotti, L., Ponti, J., Broggi, F., Kob, A., Drechsler, S., Thedinga, E., Colpo, P., Sabbioni, E., Ehret, R., Rossi, F., 2007b. Sens. Actuators B: Chem. 123, 769-778.

Cheng, X., Liu, Y.S., Irimia, D., Demirci, U., Yang, L.J., Zamir, L., Rodriguez, W.R., Toner M., Bashir, R., 2007. Lab Chip 7, 746-755.

Dal Pizzol, F., Klamt, F., Vianna, M., Schöder, N., Quevedo, J., Moreira, J.C., Walz, R. 2000. Neurosci. Lett. 291, 179-182.

Ehret, R., Baumann, W., Brischwein, M., Schwinde, A., Stegbauer, K., Wolf, B., 1997. Biosens. Bioelectron. 12, 29-41.

Giaever, I., Keese, C.R., 1991. Proc. Natl. Acad. Sci. U.S.A. 88, 7896-7900.

Giaever, I., Keese, C.R., 1993. Nature 366, 591-592.

Hultberg, B., Andersson, A., Isaksson, A., 1995. Biochim. Biophys. Acta: Mol. Cell Res. 1269, 6-12.

Inestrosa, N.C., Cerpa, W., Varela-Nallar, L., 2005. IUBMB Life 57, 645-650.

Katz, E., Willner, I., 2003. Electroanalysis 15, 913-947.

Keese, C.R., Giaever, I., 1994. IEEE Eng. Med. Biol. Mag. 13, 402-408.

Klamt, F., Dal Pizzol, F., Conte da Frota, M.L., Walz, R., Andrades, M.E., Da Silva, E.G. 2001. Free Radic. Biol. Med. 30, 1137-1144.

Leporatti, S., Vergara, D., Zacheo, A., Vergaro, V., Maruccio, G., Cingolani, R., Rinaldi, R., 2009. Nanotechnology 20, 055103.

Milhavet, O., McMahon, H.E.M., Rachidi, W., Nishida, N., Katamine, S., Mange, A. Arlotto, M., Casanova, D., Riondel, J., Favier, A., 2000. Proc. Natl. Acad. Sci. U.S.A. 97, 13937-13942.

Minseok, S.K., Wonhye, L., Yu Chang, K., Je-Kyun, P., 2008. Biotechnol. Bioeng. 101, 1005-1013.

Monnet, C., Marthiens, V., Enslen, H., Frobert, Y., Sobel, A., Mege, R.M., 2003. Eur. J. Neurosci. 18, 542-548.

Pereira, G.S., Walz, R., Bonan, C.D., Battastini, A.M.O., Izquierdo, I., Martins, V.R., Brentani, R.R., Sarkis, J.J.F., 2001. Neurosci. Lett. 301, 72-74.

Rachidi, W., Vilette, D., Guiraud, P., Arlotto, M., Riondel, J., Laude, H., Lehmann, S. Favier, A., 2003. J. Biol. Chem. 278, 9064-9072.

Smith, C., 2007. Nature 446, 219-224.

Urso, E., Rizzello, A., Acierno, R., Lionetto, M.G., Salvato, B., Storelli, C., Maffia, M., 2009. J. Membr. Biol., 10.1007/s00232-009-9219-8.

Valko, M., Morris, H., Cronin, M.T.D., 2005. Curr. Med. Chem. 12, 1161-1208.

Waggoner, D.J., Bartnikas, T.B., Gitlin, J.D., 1999. Neurobiol. Dis. 6, 221-230.

Xiao, C.D., Lachance, B., Sunahara, G., Luong, J.H.T., 2002. Anal. Chem. 74, 5748-5753.

Xiao, C., Luong, J.H.T., 2003. Biotechnol. Prog. 19, 1000-1005.

Yeon, J.H., Park, J.K., 2005. Anal. Biochem. 341, 308-315. 